\title{
Orthodontic Button-assisted Coronally Advanced Flap for Treatment of Multiple Teeth Recession: A Case Report with Literature Review
}

\author{
1Jananni Muthu, ${ }^{2}$ Sivaramakrishnan Muthanandam, ${ }^{3}$ Syed Kuduruthullah SK, ${ }^{4}$ Maher A Fattah, ${ }^{5}$ Abed EL Kaseh, \\ ${ }^{6}$ Moutassem B Khair, ${ }^{7}$ Ebtesam K Fathy
}

\begin{abstract}
Aim: The present report aims in determining the efficacy of orthodontic button assisted coronally advanced flap in the treatment of multiple teeth gingival recession and to analyze the literature evidence for the same.
\end{abstract}

Background: Gingival recession is one of the commonest periodontal problems encountered in daily practice. Coronally advanced flap is the treatment of choice for a recession in multiple teeth. But stabilizing the flap in coronally advanced position is a challenge. In this case report, orthodontic buttons are used to stabilize the coronally advanced flap for root coverage in multiple teeth

Case description: A 36-year-old male patient with multiple gingival recession in maxillary teeth reported with a complaint of sensitivity in the same region. So the case was managed with orthodontic button-assisted coronally advanced flap. Clinical periodontal parameters were recorded at baseline and the patient was followed for 1, 3 and 6 months postoperatively.

Conclusion: Clinically there was a significant improvement in the parameters from baseline to 1 and 3 months, and the results were stable until 6 months. Literature evidence also showed that coronally advanced flap with orthodontic buttons was clinically better that coronally advanced flap alone.

Clinical significance: Stabilization of the coronally advanced flap by orthodontic buttons will prevent apical movement of the

${ }^{1}$ Department of Periodontology, Indira Gandhi Institute of Dental Sciences, Sri Balaji Vidyapeeth (Deemed to be University), Puducherry, India

2Department of Oral Pathology and Microbiology, Indira Gandhi Institute of Dental Sciences, Sri Balaji Vidyapeeth (Deemed to be University), Puducherry. India

${ }^{3}$ Department of Basic Sciences-Oral Pathology, Faculty of Dentistry, Ajman University, United Arab Emirates

${ }^{4}$ Department of Surgical Sciences-Oral Surgery, Faculty of Dentistry, Ajman University, United Arab Emirates

${ }^{5}$ Faculty of Dentistry, Ajman University, United Arab Emirates

${ }^{6}$ Department of Basic Medical Science, Faculty of Dentistry, Ajman University, United Arab Emirates

${ }^{7}$ Department of Surgical Science, Faculty of Dentistry, Ajman University, United Arab Emirates

Corresponding Author: Jananni Muthu, Department of Periodontology, Indira Gandhi Institute of Dental Sciences, Sri Balaji Vidyapeeth (Deemed to be University), Puducherry, India, e-mail: jannpearl@gmail.com advanced margins and will result in better root coverage and stable results over a long period.

Keywords: Coronally advanced flap, Gingival recession, Literature review, Orthodontic button, Root coverage.

How to cite this article: Muthu J, Muthanandam S, Kuduruthullah SSK, Fattah MA, Kaseh AEL, Khair MB, Fathy EK. Orthodontic Button-assisted Coronally Advanced Flap for Treatment of Multiple Teeth Recession: A Case Report with Literature Review. World J Dent 2019;10(1):62-66.

\section{Source of support: Nil}

Conflict of interest: None

\section{AIM}

This report describes a case of multiple gingival recession successfully treated with coronally advanced flap assisted by application of orthodontic buttons and literature review of the same.

\section{BACKGROUND}

Apical migration of the marginal gingiva resulting in exposure of the root surface is termed as a gingival recession. Gingival recession is one of the very common problems encountered in periodontal practice. Kassab et al., 2003 reported almost $50 \%$ of the population had 1 or more sites with gingival recession. ${ }^{1}$ Gingival recession can pose an esthetic and functional impairment in patients, and if left untreated can result in dentinal hypersensitivity, root caries, etc. ${ }^{2}$ When such problems are faced, the gingival recession mandates treatment.

Numerous treatment modalities have been proposed, tried and reported for treatment of gingival recession. Coronally advanced flap (CAF) is considered the treatment of choice when treating multiple gingival recessions. The success of the coronally advanced flap depends on the tensionless advancement of the flap and secure suturing that will prevent apical displacement of the flap during normal function. Prato et al. reported that placement and stable positioning of the margin of the flap $2 \mathrm{~mm}$ coronal to CEJ resulted in complete root coverage. ${ }^{3}$ To achieve the stable, secure positioning of the coronally advanced flap in the same position, sling sutures secured against an orthodontic button placed on the middle of the tooth could be of great value. 


\section{CASE DESCRIPTION}

A 36-year-old male patient reported to the department with the chief complaint of sensitivity in relation to the upper left back tooth region for the past 3 months. The patient was systemically healthy, with no habit of smoking. On clinical examination, Millers class I recession was evident in 24, 25 and 26 (Fig. 1). Sensitivity on probing the exposed root was found. Very minimal inflammation was evident in the site. Oral prophylaxis and oral hygiene instructions were given to the patient, and the patient was recalled after 3 weeks. The following clinical parameters were noted at baseline, 3 weeks after initial therapy and at 1, 3 and 6 months following root coverage procedure: Probing pocket depth (PPD), Clinical attachment level (CAL), the width of keratinized tissue (KTW).

\section{Clinical Technique}

Before the surgical procedure, orthodontic buttons were fixed on the facial aspect of the teeth with composite (Fig. 2). The surgery was performed under local anesthesia (Lignocaine, with $0.2 \%$ adrenaline). After local infiltration,

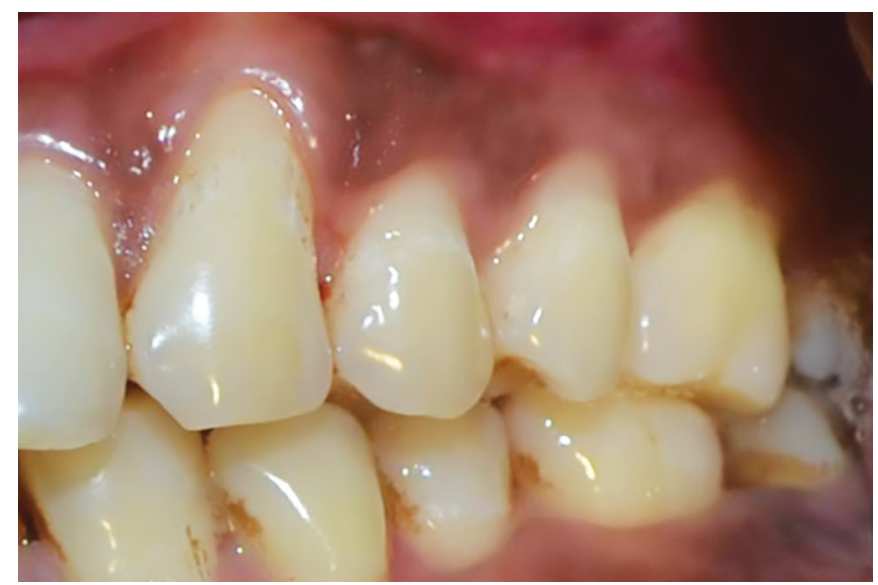

Fig. 1: Preoperative presentation with Miller's class I recession in relation to 24,25 and 26

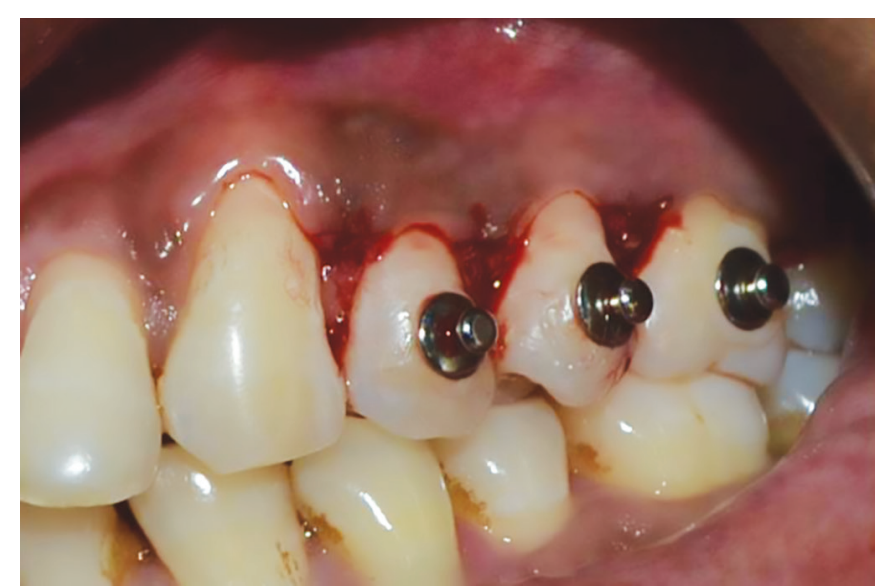

Fig. 3: Horizontal incisions given at the base of the papilla and the papilla is deepithelialized horizontal incisions were given at the base of the papilla, and the papillae were de-epithelialized. (Fig. 3) A full thickness mucoperiosteal flap was raised to expose the root surface. Beyond this point, a split thickness flap was raised beyond the mucogingival junction. The root surface was curetted and planned (Fig. 4). The flap was then coronally advanced and sutured over the deepithelialized papilla. The margins of the repositioned flap were coronal to the CEJ. The central portion of the flap was secured around the orthodontic button with suspended sutures to prevent apical migration during mastication and speech (Fig. 5). The surgical site was protected with periodontal dressing.

The patient was advised to abstain from brushing or flossing the surgical site for two weeks. Chemical plaque control with chlorhexidine was initiated and instructed to follow for 2 weeks. For pain control, plain acetaminophen was prescribed for two days. The patient was also advised to report at the earliest if the periodontal dressing was lost.

Two weeks after surgery, the patient was recalled. Pain, bleeding, swelling or discomfort due to orthodontic

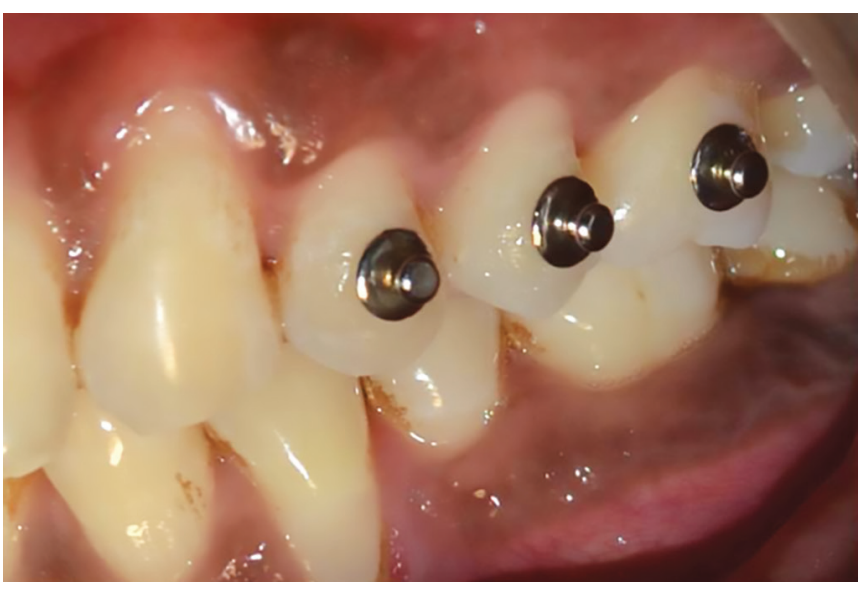

Fig. 2: Orthodontic buttons fixed on the facial aspect of the teeth with composite

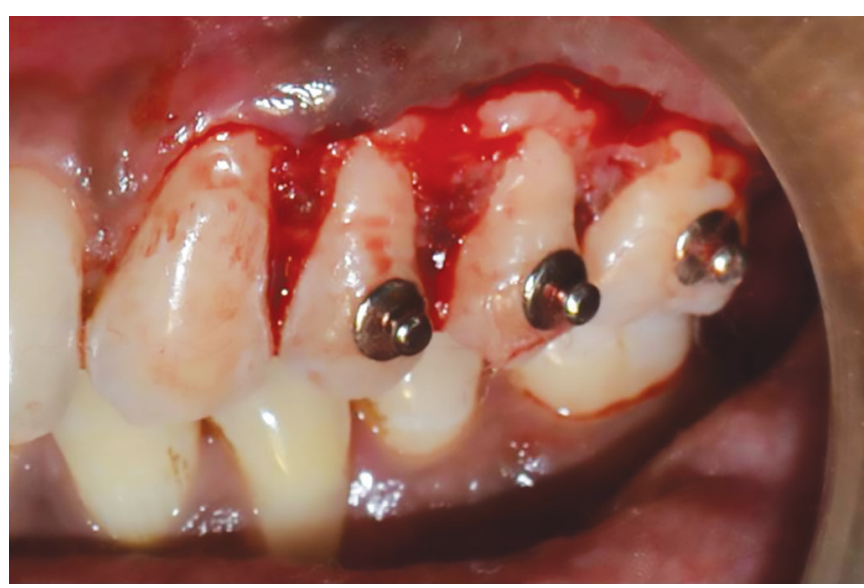

Fig. 4: Split thickness flap was raised till beyond the mucogingival junction 
buttons at the site of surgery was not experienced by the patient. The periodontal dressing was removed gently, and the area was irrigated with sterile saline. Healing was satisfactory. Sutures and the orthodontic buttons were removed, and the patient was instructed to use a soft-bristled toothbrush with roll technique for plaque control. Use of chlorhexidine was stopped. The patient was then followed up for 1 month, 3 months and 6 months postoperatively. Complete root coverage was obtained at 1-month postoperatively, and the results remained stable over 3 and 6 months (Fig. 6).

At baseline, the mean PPD of the sites was $2.1 \mathrm{~mm}$. the mean CAL was $4.3 \mathrm{~mm}$. The width of the keratinized tissue was $3.1 \mathrm{~mm}$. At the end of 6 months, the mean PPD was $2.1 \mathrm{~mm}$, CAL was $0.54 \mathrm{~mm}$ and KTW was $3.4 \mathrm{~mm}$. The comparison of clinical parameters at baseline, 1 month, 3 months and 6 months post op are presented in Table 1 .

\section{DISCUSSION}

Coronally advanced flap is the most commonly used technique to treat multiple gingival recessions. ${ }^{4}$ Treatment of multiple gingival recessions by coronally advanced flap can be difficult as securing the flap in position coronal to CEJ and preventing apical migration is a challenge. This can be overcome by securing the flap by sling sutures around the orthodontic button. This technique was first reported by Ozcelick et al. ${ }^{5}$ Aroca et al. advocated use of composite stops to secure the suspensory suture. ${ }^{6}$ This report describes a case of multiple gingival recession treated with CAF along with orthodontic buttons.

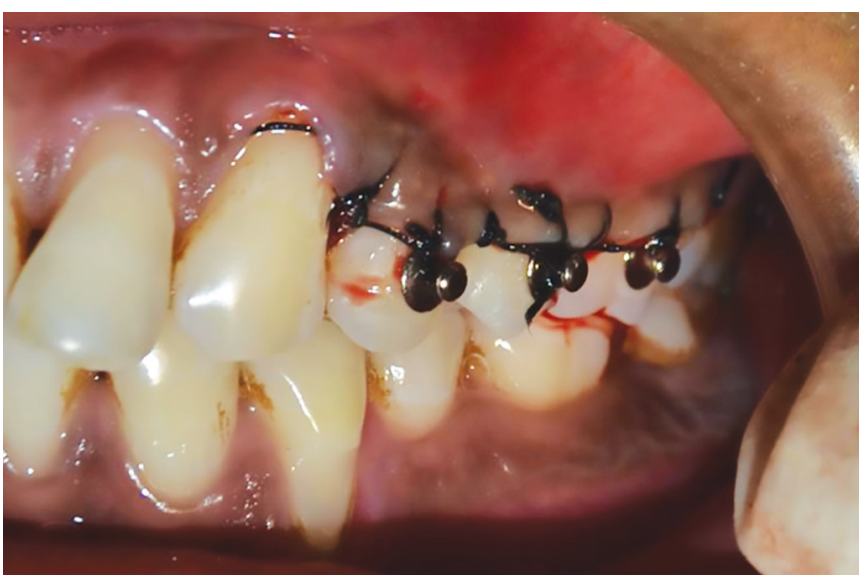

Fig. 5: Central portion of the flap secured around the orthodontic button with suspended suture
In this case, almost complete root coverage was achieved by using this technique. There was a gain in CAL and KTW from baseline to 1 month postoperatively. The results were stable for 3 months and 6 months. Numerous case reports and comparative trials reported similar findings (Table 2) ${ }^{7-18}$ The results might be attributed to the flap design and the orthodontic buttons.

The intact papilla ensured adequate blood supply to the pedicle flap. The full-split thickness flap, extended beyond mucogingival junction resulted in tensionless advancement of the flap over the root surfaces. The split thickness at the apical portion also provided the needed blood supply to the pedicle. The full thickness flap at the coronal portion guaranteed thicker biotype at the marginal gingiva thereby preventing further recession. ${ }^{7}$

The important aspect of using the orthodontic button is that it provides anchorage to the coronally advanced flap. The suspended sutures placed over the buttons ensured maximum coronal advancement and prevented apical movement.

This technique is considered as simple, cost-effective, and easy to perform and has more patient acceptance as compared to use of connective tissue grafts, emdogain or other regenerative materials. The technique has resulted in predictable, stable results with good root coverage and excellent esthetics.

\section{CONCLUSION}

Orthodontic button application to stabilize the coronally advanced flap resulted in better root coverage and stable results over 6 months postoperatively. Literature evidence

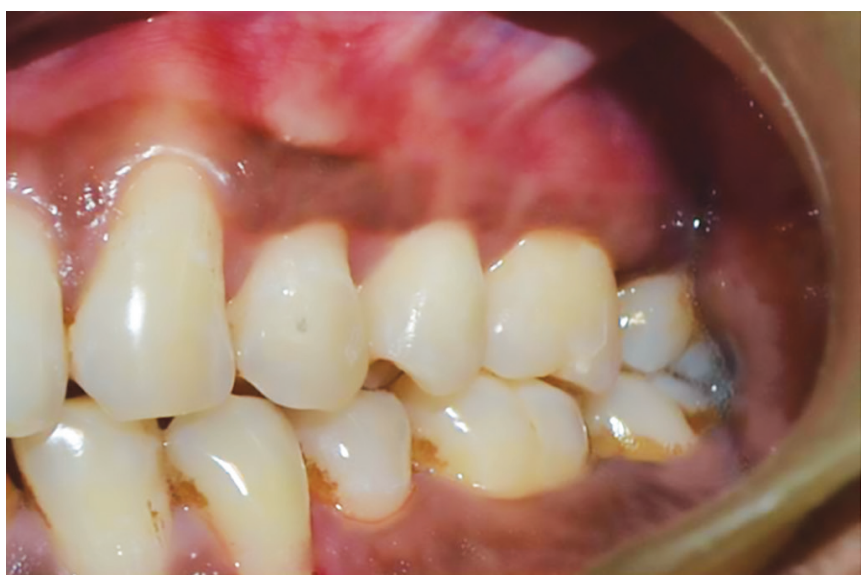

Fig. 6: 6 months postoperative presentation

Table 1: Comparison of clinical parameters at baseline and post-treatment

\begin{tabular}{lllll}
\hline Clinical parameters & Baseline & 1 month & 3 months & 6 months \\
\hline PPD $(\mathrm{mm})$ & 2.1 & 2.1 & 2.1 & 2.1 \\
CAL $(\mathrm{mm})$ & 4.3 & 1.3 & 1.2 & 1.2 \\
KTW $(\mathrm{mm})$ & 3.1 & 3.3 & 3.4 & 3.4 \\
\hline
\end{tabular}

PPD, Probing pocket depth; Cal, Clinical attachment level; KTW, Keratinized tissue width 
Table 2: Literature review

\begin{tabular}{|c|c|c|}
\hline Author & Type of report & Result and conclusion \\
\hline $\begin{array}{l}\text { Ozcelik et al., } \\
2011^{5}\end{array}$ & $\begin{array}{l}\text { Randomized } \\
\text { Control Trial }\end{array}$ & $\begin{array}{l}\text { Six months results showed that the } C A F+B \text { approach was effective for the treatment } \\
\text { of multiple gingival recessions in patients with esthetic demands. }\end{array}$ \\
\hline $\begin{array}{l}\text { Khobragade } \\
\text { et al. }\end{array}$ & $\begin{array}{l}\text { Randomized } \\
\text { Control Trial }\end{array}$ & $\begin{array}{l}\text { Both treatment modalities, i.e., } C A F \text { and } C A F+B \text { are effectual in the treatment of } \\
\text { proximate Miller's Class I and Class II gingival recession defects, but } C A F+B \text { showed } \\
\text { significantly superior clinical results. }\end{array}$ \\
\hline Khanna et al. ${ }^{9}$ & $\begin{array}{l}\text { Randomized } \\
\text { Control Trial }\end{array}$ & $\begin{array}{l}\text { Six months postsurgical evaluation showed that minimally invasive coronally } \\
\text { advanced tunnel technique with orthodontic buttons and suturing was effective and } \\
\text { predictable for the treatment of multiple recession type defects. }\end{array}$ \\
\hline Bandhari et al. ${ }^{10}$ & $\begin{array}{l}\text { Split mouth case } \\
\text { control study }\end{array}$ & $\begin{array}{l}\text { Combination of SCAF and button technique resulted in statistically significant } \\
\text { improvements in clinical parameters as compared to SCAF alone. }\end{array}$ \\
\hline Mahajan et al. ${ }^{11}$ & Case series & $\begin{array}{l}\text { Orthodontic button application resulted in better stabilization of the coronally } \\
\text { advanced flap. }\end{array}$ \\
\hline Maroo et al. ${ }^{12}$ & Case report & $\begin{array}{l}\text { CAF with orthodontic button application is very effective approach for root coverage in } \\
\text { Millers class III recession. }\end{array}$ \\
\hline Grover et al. ${ }^{13}$ & Case report & Satisfactory results in terms of root coverage, esthetics, patient comfort, etc. \\
\hline Fathima et al. ${ }^{14}$ & Case report & $\begin{array}{l}\text { The usage of the orthodontic buttons/brackets and suspended sutures with CAF technique } \\
\text { is effective method in treating multiple adjacent type gingival recessions. }\end{array}$ \\
\hline Kaushik et al. ${ }^{15}$ & Case report & $\begin{array}{l}\text { One-month postoperative results showed that the CAF combined with the orthodontic } \\
\text { button for stabilization is a very effective approach even in the treatment of Miller's } \\
\text { Class I recession defects. }\end{array}$ \\
\hline Gulati et al. ${ }^{16}$ & Case report & $\begin{array}{l}\text { The current case report demonstrates good outcomes of the CAF + B technique } \\
\text { without the use of any additional soft tissue grafts or vertical incisions, therefore, } \\
\text { endorsing the promising potential of the CAF + B technique in multiple gingival } \\
\text { recession cases. }\end{array}$ \\
\hline Bharath et al. ${ }^{17}$ & Case report & $\begin{array}{l}\text { Coronal stabilization of flap with orthodontic button resulted in better root coverage } \\
\text { outcomes. }\end{array}$ \\
\hline $\begin{array}{l}\text { Mohamed } \\
\text { et al. } 18\end{array}$ & Case report & $\begin{array}{l}\text { Three months postoperative results showed that the coronally advanced flap } \\
\text { combined with orthodontic buttons for stabilization is a very effective approach for } \\
\text { treatment of Miller's Class I recession defects. }\end{array}$ \\
\hline
\end{tabular}

also points out that the orthodontic button assisted coronally advanced flap resulted in better clinical results as compared to coronally advanced flap alone.

\section{CLINICAL SIGNIFICANCE}

Stabilization of the coronally advanced flap by orthodontic buttons will prevent apical movement of the advanced margins and will result in better root coverage and stable results over a long period.

\section{REFERENCES}

1. Kassab MM, Cohen RE. The etiology and prevalence of gingival recession. J Am Dent Assoc. 2003;134:220-225.

2. Allen EP, Miller PD., Jr Coronal positioning of existing gingiva: Short term results in the treatment of shallow marginal tissue recession. J Periodontol. 1989;60:316-319.

3. Pini Prato GP, Baldi C, Nieri M, Franseschi D, Cortellini P, Clauser $\mathrm{C}$, et al. Coronally advanced flap: The post-surgical position of the gingival margin is an important factor for achieving complete root coverage. J Periodontol. 2005;76: 713-722.

4. Chambrone, L. A. \& Chambrone, L. Subepithelial connective tissue grafts in the treatment of multiple recession-type defects. Journal of Periodontology 2006; 77: 909-916.
5. Ozcelik O, Haytac MC, Seydaoglu G. Treatment of multiple gingival recessions using a coronally advanced flap procedure combined with button application. J Clin Periodontol. 2011;38:572-580.

6. Aroca, S., Keglevich, T., Nikolidakis, D., Gera, I., Nagy, K., Azzi, R. \& Etienne, D. Treatment of class III multiple gingival recessions: a randomized-clinical trial. Journal of Clinical Periodontology 2010;37:88-97.

7. Zucchelli G, De Sanctis M. Treatment of multiple recessiontype defects in patients with esthetic demands. J Periodontol. 2000;71:1506-1514.

8. Khobragade S, Kolte A, Kolte R, Shrirao T, Potey A. Modified coronally advanced flap with and without orthodontic button application in management of multiple proximate gingival recession defects: A randomized clinical trial. Contemp Clin Dent 2016;7:544-549.

9. Khanna D, George JP, Babrawala IS, Divakaran R, Bhardwaj S, Chakraborty P. Treatment of Multiple Gingival Recessions Using a Minimally Invasive Coronally Advanced Tunnel: A Randomized Controlled Clinical Trial. J Ind Acd Periodontol 2017;19:126-137.

10. Bhandari R, Uppal RS, Kahlon KS. Comparison of semilunar coronally advanced flap alone and in combination with button technique in the treatment of Miller's Class I and II gingival recessions: A pilot study. Indian J Dent Res 2015;26:609-612.

11. Mahajan R, Khinda PK, Gill AS, Shewale S, Saravanan MSP, Bhatia N. Bracket Assisted Treatment of Multiple Gingival 
Recession Using Placental Membrane- A One Year Follow up Case Series. Int J Med Phar Case Rep 2016;6:1-4.

12. Maroo S, Grovesr HS, Luthra S. Button assisted coronally advanced flap: An innovative Ortho Perio amalgamation. J Ind Ortho Soc 2014;48:129-133.

13. Grover HS, Adosh L, Luthra S, Maroo S. Button-assisted coronally advanced flap: reclaiming the ground lost to gingival recession. Clin Dent 2014;8:15-19.

14. Fatima Z, Bey A, Mian F, Zia A. Management of Gingival Recession using Coronally Advanced Flap combined with Bracket Application: A Case Report. Journal of Advanced Medical and Dental Sciences Research 2014;2:171-175.
15. Kaushik N, Grover HS, Singh Y, Bhardwaj A. Button anchored coronally advanced flap: Perio-ortho continuum. J Dent Allied Sc i2015;4:95-98

16. Gulati M, Saini A, Anand V, Govila V. Esthetic dentistry for multiple gingival recession cases: Coronally advanced flap with bracket application. J Indian Soc Periodontol 2016;20:207-210.

17. Bharath J. Platelet-rich fibrin-a cost-effective, donor less and indigenous therapy for obtaining root coverage-a case report. Int J Dent res 2017;5:46-51.

18. Mohamed SC, Kumar SS. Button-Assisted Coronally Advanced Flap for Gingival Recession Coverage: A Case Report. Arch of Dent and Med Res 2017;3:53-56. 